\title{
Benefício de prestação continuada: perspectivas na avaliação médico-social
}

\author{
Alano do Carmo Macêdo \\ Universidade Federal de Santa Catarina (UFSC)
}

\author{
Lucia Conde de Oliveira \\ Universidade Estadual do Ceará (UECE)
}

\section{Benefício de prestação continuada: perspectivas na avaliação médico-social}

Resumo: Este artigo propõe reflexões acerca da avaliação médico-social da pessoa com deficiência no acesso ao Benefício de Prestação Continuada da Lei Orgânica da Assistência Social. A abordagem qualitativa da pesquisa possibilitou a análise do movimento to real, a partir do processo de trabalho de assistentes sociais e médicos peritos do INSS. Foram realizadas entrevistas com os referidos profissionais de agências da previdência social de Fortaleza-CE. Os interlocutores revelaram uma realidade, com relação ao modus operandi desse processo avaliativo, que referenda a ausência de uniformidade no entendimento do modo de avaliar a pessoa com deficiência que pleiteia o BPC.

Palavras-chave: Benefício de Prestação Continuada. Pessoa com deficiência. Avaliação médico-social.

\section{Continued Payment Benefit: Perspectives on the Medical-Social Evaluations}

Abstract: This article reflects on the social and medical evaluation of people with disabilities for access to the Continued Payment Benefit under Brazil's Organic Social Assistance law. The qualitative approach of the study allowed an analysis of changes in the reality, based on the work process of social assistants and examining doctors from the National Social Security Institute (INSS). Interviews were conducted with the professionals from the Social Security agency from Fortaleza, Ceara State. The interlocutors revealed an absence of uniformity in the modus operandi of the evaluation process, which leads to a lack of uniformity in understanding the form of evaluating a person with a disability who requests the Benefit.

Keywords: Continued Payment Benefit. People with disabilities. Medical-social evaluation. 


\section{Introdução}

O Benefício de Prestação Continuada da Lei Orgânica da Assistência Social (BPC/Loas) é um benefício operacionalizado pelo Instituto Nacional do Seguro Social (INSS), sendo custeado com recursos financeiros provenientes do Fundo Nacional de Assistência Social (FNAS). Consiste na transferência mensal e temporária $^{1}$ de renda, sem contrapartidas, no valor de um salário-mínimo, destinado às pessoas com deficiência ${ }^{2} \mathrm{e}$ também aos/às idosos/as com 65 anos de idade ou mais, ambos/as com renda per capita familiar inferior a $1 / 4$ do salário-mínimo (BRASIL, 1993, 2007b). No caso da pessoa com deficiência, após habilitação do benefício, ela é direcionada para ser avaliada por assistente social e médico/a perito/a, ambos/as do INSS, em relação à deficiência e ao grau de impedimento (BRASIL, 2011).

$\mathrm{O}$ interesse pela investigação tem sua gênese com as inquietações vivenciadas no processo de trabalho enquanto assistente social do INSS, bem como no âmbito acadêmico e nas articulações junto aos movimentos sociais das pessoas com deficiência. Do exposto, surgem algumas indagações: até que ponto o paradigma biomédico, centrado no indivíduo, foi superado nas práticas avaliativas dos/as profissionais envolvidos/as (médicos/as e assistentes sociais)? Quais as repercussões dessas concepções e práticas no reconhecimento e materialização do acesso, garantia e ampliação desse importante direito social às pessoas com deficiência?

Nesse sentido, esse artigo pretende apontar os avanços e desafios do modelo de acesso ao BPC centrado na Classificação Internacional de Funcionalidade, Incapacidade e Saúde (CIF) ${ }^{3}$; evidenciar as tensões que permeiam os saberes e as práticas dos/as profissionais que operacionalizam os critérios de avaliação da deficiência e do grau de impedimento, a priori, referenciadas na CIF e expressas em um instrumental de avaliação médico-social; e, por fim, apontar as possíveis contribuições que esse modelo pode oferecer para ampliar o acesso a esse-direito social.

\section{Percurso metodológico}

O primeiro momento da pesquisa foi marcado por um estudo bibliográfico, documental e por visitas aos locais da pesquisa. Em seguida, foram definidos os procedimentos metodológicos para a produção dos dados. As entrevistas foram realizadas com médicos/as peritos/as e assistentes sociais, e também foram enviados questionários por correio eletrônico para quatro membros do Grupo de Trabalho Interministerial (GTI), que participaram do processo de elaboração do modelo de avaliação da pessoa com deficiência baseado na CIF, considerando que eles trariam informações não encontradas em documentos oficiais. Importa destacar que apenas dois/duas destes/as interlocutores/as responderam. O roteiro de entrevista contemplou dados de identificação do/a profissional envolvido/a no processo avaliativo, considerando: os recortes de gênero, etário; tempo de atuação no INSS; formação profissional; avaliação sobre o atual modelo de avaliação da deficiência e do grau de impedimento 4 implementado pelo INSS e MDS desde junho de 2009; as tensões entre assistentes sociais e médicos/as peritos/as; os dilemas e resistências dos/as profissionais que operacionalizam a avaliação; outros assuntos de interesse da investigação. O roteiro, também, foi elaborado considerando as aproximações e os aprofundamentos teórico-empíricos, sendo realizado, antes de sua aplicação, um pré-teste, no qual identificamos o tempo de execução, bem como a necessidade de reformulações, acréscimos de assuntos que não estavam contemplados e a retirada de algumas questões que se mostraram dispensáveis. As entrevistas foram realizadas com seis assistentes sociais e oito médicos/as peritos/as que atuam em Agências da Previdência Social (APS) da Gerência Executiva Fortaleza (Gexfor), do INSS. Os critérios para escolha dos/as entrevistados/as foram: atuar em APS da Gexfor, localizada na cidade de Fortaleza, e realizar avaliação social ou médica no cotidiano profissional há pelo menos um ano.

Por fim, ocorreu a descrição, o tratamento e a análise dos dados coletados na pesquisa. Durante a análise, as questões foram agrupadas em tópicos específicos e interpretadas considerando as falas comuns e divergentes apresentadas pelos/as interlocutores/as da pesquisa, ou seja, comparando e confrontando posições, extraindo significados das falas e registros, além de outras expressões não ditas.

Para atender à garantia do sigilo dos/as entrevistados/as, utilizamos, para a apresentação de trechos dos depoimentos, siglas referentes ao cargo do/a profissional seguido de numeração, ordenada de acordo com a sequência das entrevistas. No caso dos membros do GTI, foram identificados da seguinte forma: GTI 1 e GTI 2.

Cabe destacar que no desenvolvimento da pesquisa de campo foram respeitadas as normas éticas que regem a pesquisa científica com seres humanos, conforme Resolução 466/2012 do Conselho Nacional de Saúde (CNS), solicitando-se o consentimento livre e esclarecido dos/as entrevistados/as, bem como a autorização para realizar as observações e a preservação do anonimato dos/as informantes. O projeto foi aprovado pelo Comitê de Ética em Pesquisa da Universidade Estadual do Ceará. 


\section{Modelo médico-social no acesso ao BPC}

Tendo em vista a consideração judicial ${ }^{5}$ e as frequentes indicações das conferências municipais, estaduais e nacionais acerca da limitação no modo de avaliação da defíciência e do grau de impedimento das pessoas com deficiência, culminando na dificuldade de acesso ao BPC, o governo institui um grupo interministerial para estudar novos mecanismos de elegibilidade nesse processo. De vários estudos, inclusive buscando vivências de outros países, encontrou-se a experiência inspiradora no México com o uso da Classificação Internacional de Funcionalidade, Incapacidade e Saúde (CIF), ${ }^{6}$ conforme apontam os/as informantes do GTI:

não houve alternativa que a superasse como proposta de base para a confecção dos instrumentos de avaliação. A princípio chegamos a rejeitá-la, devido à sua complexidade, mas depois nos familiarizamos. Ela foi um aprendizado crescente (...) A experiência do México, fundamentada na pontuação de todos os domínios e unidades de classificação (...), foi o critério que melhor nos norteou em relação à CIF (GTI 1).

A partir do momento em que compreendemos tal lógica, a confecção do instrumento e qualificação de todos os seus campos não foi difícil. O desafio era definir os critérios pertinentes às combinações que concederiam o benefício e quais destas os indefeririam. Isso precisou ser criado, pois não se encontrou qualquer instrumento de avaliação na literatura elaborado nessas bases (GTI 2).

Visando a institucionalizar um modelo de avaliação com referencial na CIF, tendo como propósito materializar as indicações feitas em linhas atrás, foi instituído o Decreto n. 6.214/2007 e suas alterações posteriores, o qual no seu artigo 16 recomenda que o reconhecimento inicial de direito à pessoa com deficiência, pleiteante a esse benefício, ficará sujeito a avaliação da deficiência e do grau de impedimento com base nos princípios da CIF e, ainda, que esse processo seja composto de avaliação médica e social realizadas, respectivamente, por médico/a perito/a e assistente social do INSS. Com a preparação técnica dos ministérios para colocar em prática essa nova modalidade de acesso ao BPC, em junho de 2009, inicia-se efetivamente o atendimento dos/ as requerentes fazendo uso desses novos critérios.

\subsection{A relação entre a Classificação Internacional de Funcionalidade, Incapacidade e Saúde (CIF) e a avaliação médico-social}

Neste tópico, abordamos a relação que os/as interlocutores/as da pesquisa concatenam entre a CIF e a avaliação biopsicossocial, compreendendo as conexões estabelecidas a partir das concepções que os/as profissionais envolvidos/as nesse processo elaboram.

Entendemos que a CIF problematiza aspectos relacionados à funcionalidade e à incapacidade, articulando com o diagnóstico da condição de saúde, revelando os limites e as possibilidades das atividades que o indivíduo pode desenvolver ou mesmo participar em seu cotidiano, levando em consideração as funções dos órgãos ou sistemas e estruturas do corpo, bem como as barreiras arquitetônicas/geográficas/atitudinais nas atividades e participação social no contexto ambiental que o/a requerente está inserido. Para a Organização Mundial da Saúde (OMS), existe uma relação de complementariedade entre CID-107 e CIF. Nesse sentido, a defesa é de que o diagnóstico, quando associado à funcionalidade, poderá fornecer um processo avaliativo mais amplo sobre a condição de saúde de uma pessoa ou população. Assim, torna-se mais fácil compreender quando duas pessoas acometidas pelo mesmo tipo de neoplasia maligna, por exemplo, serão, provavelmente, afetadas em suas funcionalidades de formas distintas.

Segundo os/as entrevistados/as, os instrumentais norteados pela CIF possibilitam compreender o/a requerente com lesão e/ou doença de forma contextualizada, considerando as múltiplas relações sociais que este/ a estabelece, o que é apontado, por ambas as categorias (médicos/as peritos/as e assistentes sociais), como um avanço em relação ao modelo anterior.

ela analisa o indivíduo como um todo. A concepção social, o que faz, como é que faz, como se porta a doença dele num grupo, o que acontece com esse grupo, o que vai acontecer do ponto de vista de atividade laborativa também (MP-01).

a CIF (...) foi um avanço, porque você consegue perceber o indivíduo não só na sua doença, mas todo o contexto, a conjuntura que ele traz, ou seja, como parte de uma sociedade com diversas barreiras no acesso às políticas públicas, por exemplo (AS-01). 
A maioria dos/as profissionais entrevistados/as corrobora a abordagem da CIF numa perspectiva biopsicossocial, que discute os componentes de saúde nas funções e estruturas do corpo, bem como no aspecto social. Dessa forma, esse modelo é diferenciado do biomédico por fazer considerações para além dos aspectos biológicos, ao levar em conta, também, as percepções psicológicas (individual) e a interação social. Essa proposta avaliativa, conforme as análises de Farias e Buchalla (2005, p. 189), tem em seu cerne que "cada nível age e sofre ação dos demais, sendo todos influenciados pelos fatores ambientais".

No entanto, identificamos na fala de um/a médico/ perito/a entrevistado/a uma avaliação "diferenciada". Ele/a reconhece as vantagens do instrumento, mas acredita que a proposta da CIF não é seguida por sua categoria, mas sim a visão tradicional do modelo biomédico centrado na clínica. Esse movimento, conforme o/ a referido/a interlocutor/a, é referendado pelo próprio contexto institucional.

quando a CIF surgiu (...) ela representava uma perspectiva de uma abordagem mais intersetorial, mais abrangente do processo saúde-doença e iria, de certa maneira, contribuir para que essa visão do médico perito não se restringisse apenas aos aspectos clínicos ou médicos, mas pudesse compreender a questão da incapacidade do trabalho a partir de elementos ligados a outros setores, trabalho, lazer, condições econômicas, dinâmica familiar, enfim, situação de inclusão ou exclusão na sociedade e tal (...) seria um instrumento pra essa abordagem mais abrangente e representaria (...) esse avanço de qualidade na abordagem médicopericial. No entanto, isso não ocorreu, quer dizer, concretamente a CIF não foi adotada pelos médicos peritos, até por uma insuficiência no direcionamento dos níveis hierárquicos da gestão do INSS. Então existe hoje uma dicotomia entre a visão médico-pericial e a visão social, onde a incapacidade de trabalho avaliada pelo médico perito tá muito mais embasada na clínica do que nessa conjunção de fatores que poderiam contribuir pra entender a incapacidade para o trabalho (MP-02).

Para Martins (2004), como os/as médicos/as tradicionalmente detêm o poder de decidir, talvez não admitam partilhar essa "força" com outro/a profissional. Tais argumentações podem ser reforçadas pelo relato de outro/a profissional que defende a objetividade da avaliação médica, sem a interferência da avaliação social, mesmo reconhecendo que tal avaliação pode complementar a "parte médica":

a avaliação médica (...) é objetiva, (...) sem ser interferida pela avaliação social, a avaliação social ela já vai somar junto com a avaliação médica pra concessão ou indeferimento do benefício (...) Assim, não precisa o social influenciar nos aspectos médicos (MP-07).

Nesse sentido, fica evidenciado que nem todos/as os/as profissionais conseguiram "incorporar" o escopo de análise proposto pela CIF. Um dos informantes do GTI oferece pistas para interpretação do fenômeno, ao apontar que "A cultura institucional do INSS que privilegia a visão do seguro e a responsabilidade individual do trabalhador na garantia de sua proteção social, repercutiu (e ainda repercute) na operacionalização do BPC" (GTI-1). Tal aspecto, permeado pela lógica do seguro, na qual avalia a capacidade para o desempenho das funções laborais, pode rebater de forma negativa no modus operandi do BPC. Importa destacar que a função pericial é desenvolvida exclusivamente pelos/as médicos/as, quando se trata da previdência social. Cabe reforçar que a finalidade da assistência social, como política pública, é distinta e com a CIF essa exclusividade, no âmbito previdenciário, foi quebrada, tensionando a hegemonia médica dentro da instituição.

Compreendemos que esse modelo introduziu um novo paradigma para pensar e problematizar as deficiências, defendendo que elas não são apenas uma consequência das condições de saúde/doença, mas são determinadas, também, pelo contexto do meio ambiente físico e social, pelas diferentes percepções culturais e atitudes em relação à deficiência, pela disponibilidade de serviços e legislações públicas. Assim, a CIF não tem como objetivo final e único apenas a contribuição na constatação ou não de determinado grau de deficiência e limitação no desempenho de determinadas atividades, mas também contribuir para o fomento das políticas públicas, considerando os elementos que emergem nesse contexto.

Esse processo avaliativo, à luz de um instrumental embasado na CIF, considera, quanto à avaliação social, os fatores ambientais, sociais e pessoais. Já a avaliação médica levará em conta a deficiência nas funções e nas estruturas do corpo, e ambas considerarão a limitação do desempenho de atividades e a restrição da participação social, segundo suas especificidades. Interessa problematizar como e o que orienta, em termos de fundamentação teórico-metodológica e ético-política, esses/as profissionais no processo de trabalho cotidiano. Assim, constatamos que a maioria das assistentes sociais pondera a relevância de compreender a ação para além do instrumental, sendo este apenas um norte para a avaliação não ser fragmentada, descolada da processualidade histórica da qual o/a requerente é parte: "você tem que ter domínio sobre o conceito de pessoa com deficiência, acessibilidade, políticas públicas, cidadania, saúde, Estado, dentre outras categorias” (AS-05). 
Desvendando a aparência dos processos, adentrando o campo da essência, constatamos que alguns discursos revelam que o/a médico/a perito/a utiliza o arcabouço avaliativo dos benefícios previdenciários por incapacidade para realizar a avaliação do/a requerente o qual pleiteia o BPC. Cabe ressaltar que tais benefícios, inseridos na lógica do seguro, privilegiam o modelo biomédico:

o médico perito passou a se instrumentalizar pelos mesmos protocolos que orientam a concessão de auxíliodoença. São os mesmos protocolos, são as mesmas avaliações, os mesmos critérios, os mesmos parâmetros pra incapacidade para o trabalho, por exemplo, na área de oftalmologia, na área de ortopedia, clínica médica, cardiologia e psiquiatria, que são os protocolos que a gente tem hoje. Eles são orientadores também da avaliação do BPC. Então, na verdade, não existe nenhuma outra forma de o médico perito se referenciar se não essa. Então, por exemplo, se o indivíduo está desempregado, nunca contribuiu, tem 62 anos e, com certeza, ele não vai conseguir se inserir no mercado de trabalho por conta de uma doença cardiológica ou de uma doença pulmonar ou de uma doença reumática, a abordagem que o médico perito vai ter é a mesma clínica do auxílio-doença, e ele vai pontuar hoje através do mecanismo do Sibe ${ }^{8}$, ele vai pontuar de acordo com esse referencial. Se a dor e a limitação funcional for leve, vai ser leve, independentemente se ele tenha 62 anos, e com aquela incapacidade ele não vai conseguir trabalhar (MP-02).

Nas falas, constatamos o tensionamento, ainda presente, do modelo médico versus o modelo social, sendo o primeiro aquele que enfatiza, conforme a CIF (2003, p. 32), "a incapacidade como um problema da pessoa, causado diretamente pela doença, trauma ou outro estado de saúde, que requer assistência médica fornecida através de tratamento individual". Em outros termos, defende que a questão da assistência médica deve ser priorizada, e na arena política a solução é uma reforma apenas da saúde pública. Já a perspectiva social defende que esse é um problema criado socialmente, sendo uma teia complexa de desigualdades e paradoxos fincados na sociedade contemporânea, orientada pela lógica do capital. Trata-se de um embate que não deve ser travado apenas no campo da saúde, mas das demais políticas públicas.

Sabemos que o qualificador adotado em cada domínio não representa a soma das unidades de classificação ou qualquer resultado matemático a priori. É de responsabilidade do/a profissional graduar a barreira ou dificuldade de cada domínio, tendo como respaldo o arcabouço teórico-metodológico. Com isso, é relevante debater se os/as interlocutores/as desta pesquisa estão se percebendo capacitados/as para realizar o processo avaliativo da pessoa com deficiência que pleiteia o BPC. A maioria dos/as profissionais, em ambas as categorias, apesar do esforço individual, aponta a necessidade de a instituição viabilizar a capacitação continuada, considerando as constantes alterações nos instrumentais:

eu acho que a gente poderia ter uma política de capacitação constante, eu realmente tenho conhecimentos pra poder aplicar e realizar de fato a avaliação, mas assim... Volta e meia temos que nos debruçar, estudar para que isso não se torne uma tarefa rotineira, (...) precisamos de espaço para debater (AS-06).

olha, eu faço o possível para tal, (...) a gente tem a base teórica, tá sempre lendo e se informando, dá sempre uma revisada na CIF, nos seus critérios, nas diretrizes do INSS, pra tentar fazer o trabalho da melhor maneira possível (MP-01).

Destacamos a fala de um/a profissional da área médica que enfatiza suas experiências pessoais como norteadoras do seu fazer profissional. Esse contexto potencializa, para além da subjetividade, os referenciais de análise no processo de trabalho.

a inserção na saúde pública, pensando assim individualmente, viabiliza certa capacidade de avaliação médico-social, para, além disso, uma capacidade de avaliação histórico-social, uma avaliação do contexto político, econômico e social do nosso País (...) o fato de eu me inserir em movimentos sociais, em ter trabalhado muito com movimento sindical, com movimentos populares, então isso me possibilita uma compreensão que eu idealizo, que é a compreensão da demanda do BPC a partir de questões de ordem interdisciplinar, intersetorial (MP-02).

Outra fala sinaliza para algo além da ausência de capacitação continuada: revela o não acesso às condições técnicas de trabalho, o que pode rebater negativamente no movimento de reconhecimento inicial de direito ao benefício: "falta reciclagem, (...) falta um olhar voltado para o humano, além de insumo no próprio consultório, (...) então, às vezes, eu não faço um determinado exame porque não tem material" (MP-03). 
Os relatos revelam que a graduação dos domínios pertinentes à avaliação médico-social sofre o espraiamento não só das condições subjetivas, mas das objetivas, o que rebate diretamente na concessão ou mesmo indeferimento do benefício. Em nossas análises, verificamos que os/as interlocutores/as desta pesquisa revelam um sentimento que transita ora na culpabilização do indivíduo, que deve buscar sua capacitação, ora na compreensão de que é algo bem mais complexo, considerando que estamos diante de um contexto institucional com espraiamentos das orientações neoliberais. É importante pontuar que não estamos defendendo nenhuma espécie de messianismo ou mesmo fatalismo, ou ainda uma perspectiva funcionalista, mas devemos compreender os limites e possibilidades da ação de ambos os profissionais, considerando as problematizações em tela.

\subsection{E o que sugerem os/as interlocutores/as desta pesquisa?}

Alguns/mas profissionais revelam a necessidade de espaços de interação entre os/as avaliadores/as que operacionalizam o instrumental com o intuito de superar concepções dicotômicas, devido, principalmente, ao fato de esta avaliação ser realizada em tempo e espaço diferentes.

Eu acho que deveria ter um entrosamento maior entre o serviço social e o serviço médico e que tudo que é avaliado deveria ser discutido um pouco mais, eu acho que esse modelo foi um pouco imposto de cima pra baixo sem termos dado a oportunidade de a gente estudar, de a gente sentar pra debater, nem médico sozinho, nem médico junto com as assistentes sociais (MP-04).

Um/a dos/as interlocutores/as da pesquisa inicia sua fala apontando a ausência de reuniões técnicas por categoria, bem como de espaços de discussões coletivas entre os/as profissionais. Sugere que as reuniões técnicas deveriam acontecer de forma intersetorial, ou seja, com a participação de representantes de outras políticas sociais, bem como dos demais sujeitos políticos no bojo da sociedade, com o intuito de socializar os processos de trabalho de forma contextualizada, evitando equívocos de análise. Dessa forma, observamos uma demanda legítima com a intenção de superar um provável endogenismo nesse processo:

os médicos peritos não se reúnem mais há quatro meses (...). As reuniões estão proibidas, (...) eu entendo que (...) as reuniões técnicas sejam reuniões intersetoriais, (...) reuniões não só multiprofissionais, mas (...) que a gente possa trazer o movimento sindical pra discutir com os médicos peritos, pra ouvir o pensamento dos trabalhadores, que os movimentos populares tragam pra ouvir o que pensa a população a respeito desses problemas em que a seguridade e a, por conseguinte, previdência enfim atuam, e que possam ter nas reuniões todos os profissionais que atuam na seguridade social, inclusive a interlocução com o SUS, que eu acho que esse é um outro nó. (...) ela não existe tanto, o médico perito demoniza os médicos assistentes dos profissionais que acham que são médicos, que forçam a barra, enfim, ou que não fornecem informações etc., sem entender o porquê disso. Como os médicos assistentes, os profissionais da área de saúde demonizam a perícia médica, também, sem entender o porquê do que muito do que acontece aqui acontece dessa forma. (MP-02).

Reforçamos a importância e a necessidade de que o/a profissional, ao realizar a avaliação médicosocial, deva lançar um olhar abrangente, percebendo a concatenação presente entre fatores ambientais, atividades e participação, e funções do corpo. Assim, compreendemos que médicos/as peritos/as e assistentes sociais podem avançar ao interpretar as múltiplas expressões da questão social presentes nesse contexto, problematizando junto aos movimentos sociais, contribuindo, assim, para fomentar estudos e pesquisas que suscitem políticas sociais universais ou mesmo tensioná-las em tempos de desigualdades e paradoxos.

Constatamos que são múltiplas as mediações constitutivas do tecido das relações sociais envolvendo esse processo de produção e reprodução social da vida em suas diversas expressões. São essas relações que constituem a sociabilidade humana, implicam âmbitos diferenciados e uma trama que envolve o social, o político, o econômico, o cultural, o religioso, o gênero, a idade, a etnia etc., dimensões que o/ a profissional, no manejo do instrumental avaliativo, defronta-se cotidianamente, exigindo conhecimento e posicionamento críticos, tanto na dimensão explicativa quanto na interventiva. Tudo isso sem perder de vista o contexto institucional, por vezes, adverso. 


\section{Considerações}

Temos um modelo avaliativo pautado nas orientações da CIF que atende, a priori, as demandas históricas da sociedade civil organizada. Os/as assistentes sociais do INSS sempre pautaram a defesa de uma proposta de avaliação para além do viés médico, desde a gênese da operacionalização do BPC, em 1996. Mesmo quando o serviço social, por um breve período, deixou de fazer parte da estrutura do INSS, os/as assistentes sociais continuaram suas articulações políticas no sentido de fortalecer um movimento que culminasse na derrocada do modelo meramente biomédico então vigente. É importante fazermos esta observação, pois, apesar de estarmos em um espaço sócio-ocupacional regido pela lógica do seguro, defendemos outra proposta: a universalização das políticas sociais (assistência social, saúde, previdência, educação, entre outras). Mesmo cientes dos embates para alcançá-la nesta sociabilidade, o seu tensionamento é fundamental, pois é isso que definirá se as conquistas serão mais ou menos elásticas.

\section{Os/as assistentes sociais do} INSS sempre pautaram a defesa de uma proposta de avaliação para além do viés médico, desde a gênese da operacionalização do BPC, em 1996.

Constatamos que nem todos/as os/as profissionais em seus processos de trabalho seguem as diretrizes norteadoras do modelo avaliativo fundamentado na CIF. No caso da avaliação médica, a maioria dos/as profissionais responsáveis por essa análise referenda a ausência de uniformidade no entendimento do modo de avaliar a pessoa com deficiência que pleiteia o BPC.

Observarmos a presença, ainda que velada, de uma disputa entre as perspectivas biomédica e médico-social, apesar de a construção do instrumental ter sido pautada nesta última proposta, o que revela questões para além da padronização desse instrumento utilizado no processo avaliativo. Dessa forma, compreendemos que o debate perpassa não só as condições objetivas, neste caso o instrumental, mas as subjetivas desse movimento, o que exige posicionamento crítico para aclarar as diferentes concepções.

Concluímos apontando a necessidade de problematizarmos a ampliação dos espaços de discussões, pois os/as profissionais que operacionalizam o processo avaliativo do BPC indicam a ausência desses mecanismos de interação, não só entre os/as profissionais, mas com a participação, também, das pessoas que pleiteiam o benefício. Assim, propomos a materialidade de um debate mais amplo, com abertura para a participação da sociedade civil imbricada direta ou indiretamente no processo, com avaliação continuada não só da operacionalidade do instrumental em si, mas, também, pautando a discussão sobre a ampliação das categorias que participam dessa técnica avaliativa.

\section{Referências}

BOSCHETTI, I. Seguridade social e trabalho: paradoxos na construção das políticas de previdência e assistência social no Brasil. Brasília: Letras Livres/ UnB, 2006.

BRASIL. Ação Civil Pública n. 2007.30.00.000204.-0, de 11 de abril de 2007. Proposta pelo Ministério Público Federal e Defensoria Pública Federal contra o Instituto Nacional de Seguro Social (INSS), que trata dos critérios de elegibilidade do Benefício de Prestação Continuada. Brasil, 2007a.

. Constituição da República Federativa do Brasil. Brasília: Gráfica do Senado Federal, 1988. Brasil, 1988.

. Decreto n. 6.214, de 26 de setembro de 2007. Regulamenta o Benefício de Prestação Continuada da Assistência Social devido à pessoa com deficiência e ao idoso de que trata a Lei n. 8.742, de 07 de dezembro de 1993, e a Lei n. 10.741, de $1^{\circ}$ de outubro de 2003, acresce parágrafo ao art. 162 do Decreto n. 3.048, de 06 de maio de 1999, e dá outras providências. Brasil, 2007b.

. Decreto n. 7.617, de 17 de novembro de 2011. Altera o Regulamento do Benefício de Prestação Continuada, aprovado pelo Decreto no 6.214, de 26 de setembro de 2007, e dá outras providências. Brasil, 2011.

. Lei n. 8.742, de 08 de dezembro de 1993. Dispõe sobre a Lei Orgânica da Assistência Social. Diário Oficial da União, 1993. Brasil, 1993.

. Ministério do Desenvolvimento Social e Combate à Fome (MDS). Avaliação de pessoas com deficiência para acesso ao Benefício de Prestação Continuada da Assistência Social: um novo instrumento baseado na Classificação Internacional de Funcionalidade, Incapacidade e Saúde. Brasília, DF: MDS, 2007c.

Portaria Conjunta MDS/INSS n. 1, de 29 de maio de 2009. Institui Instrumentos para a avaliação da deficiência e do grau de incapacidade de pessoas com deficiência requerentes ao Benefício de Prestação Continuada da Assistência Social - BPC, 
conforme estabelece o art. 16, $\S 3^{\circ}$, do Decreto n. 6.214, de 26 de setembro de 2007, alterado pelo Decreto n. 6.564, de 12 de setembro de 2008.

CLASSIFICAÇÃO INTERNACIONAL DE FUNCIONALIDADE, INCAPACIDADE E SAÚDE. São Paulo: Edusp, 2003.

FARIAS, N.; BUCHALLA, C. M. A classificação internacional de funcionalidade, incapacidade e saúde da organização mundial da saúde: conceitos, usos e perspectivas. Rev. Bras. Epidemiol. [online], v. 8, n. 2, p. 187-193, 2005.

MARTINS, A. Biopolítica: o poder médico e a autonomia do paciente em uma nova concepção de saúde. Interface, Botucatu, v. 8, n. 14, p. 21-32, fev. 2004.

NUBILA, H. B. V.; BUCHALLA, C. M. O papel das Classificações da OMS - CID e CIF nas definições de deficiência e incapacidade. Rev. Bras. Epidemiol. [online], v. 11, n. 2, p. 324-335, 2008.

\title{
Notas
}

1 Conforme redação do artigo 42 do Decreto 6.214/2007, “O Benefício de Prestação Continuada deverá ser revisto a cada dois anos, para avaliação da continuidade das condições que lhe deram origem, conforme dispõe o art. 21 da Lei n. 8.742, de 1993, passando o processo de avaliação a integrar o Programa Nacional de Monitoramento e Avaliação do Benefício de Prestação Continuada".

2 Existe um debate sobre como devem ser apresentadas as nomenclaturas sobre as pessoas que vivem a experiência da deficiência. Neste artigo, será utilizada a expressão "pessoa com deficiência” para representar todo o conjunto das pessoas que sofrem opressão pelo corpo, pois é a designação utilizada pelo Conselho Nacional dos Direitos das Pessoas com Deficiência.

3 "A CIF representa uma mudança de paradigma para se pensar e trabalhar a deficiência e a incapacidade, constituindo um instrumento importante para avaliação das condições de vida e para a promoção de políticas de inclusão social” (FARIAS; BUCHALLA, 2005, p. 187).

4 Aexpressão "grau de impedimento" foi acrescida pelo Decreto n. 7.617, de 17 de novembro de 2011. Tal prerrogativa visa a enquadrar o requerente nas situações de "impedimento de curto/médio prazo" ou “impedimento de longo prazo", ressaltando que a primeira situação reverbera de forma negativa na concessão do benefício, enquanto o segundo mantém o resultado da avaliação dos profissionais, que pode ser deferimento ou indeferimento do benefício. O critério só pode ser acionado pelo médico perito.

5 Uma ação civil pública movida pelo Ministério Público Federal e pela Defensoria Pública da União contra o INSS teve como objetivo requerer que as APS de todo o País deixassem de exigir, para a concessão do BPC, que a pessoa com deficiência seja incapaz para os atos da vida civil (voto, casamento).

6 O objetivo geral da classificação é proporcionar uma linguagem unificada e padronizada e uma estrutura que descreva a saúde e os estados relacionados à saúde. Ela define os componentes da saúde e alguns componentes do bem-estar relacionados à saúde (tais como educação e trabalho) (CIF, 2003, p. 13).

7 Para Nubila e Buchalla (2008), a Classificação Internacional de Doenças (CID) veio sendo estruturada, por mais de um século, primeiro como forma de responder à necessidade de conhecer as causas da morte. Passou a ser alvo de crescente interesse e seu uso foi ampliado para codificar situações de pacientes hospitalizados, depois consultas de ambulatórios e atenção primária, sendo seu uso sedimentado também para morbidade. A sua Décima Revisão, denominada "Classificação Estatística Internacional de Doenças e Problemas Relacionados à Saúde”, ou de forma abreviada “CID-10", é a mais recente revisão da "Classificação de Bertillon” de 1893, que era inicialmente uma classificação de causas de morte, e apenas a partir da Sexta Revisão passou a ser uma classificação que incluiu todas as doenças e motivos de consultas, possibilitando seu uso para situações de morbidade.

8 OSistema Integrado de Benefícios (Sibe) é um programa que articula o reconhecimento inicial de direito relativo aos benefícios previdenciários e assistenciais.

\author{
Alano do Carmo Macêdo \\ alanomacedo@yahoo.com.br \\ Doutorando em Serviço Social pela Universidade Federal de Santa Catarina (UFSC) \\ Assistente Social do Instituto Nacional do Seguro Social (INSS)
}

\section{INSS}

Rua: Pedro Pereira, 383, Centro

Fortaleza - Ceará - Brasil

CEP: 60.035-000

\section{Lucia Conde de Oliveira}

Universidade Estadual do Ceará (UECE)

conde.lucia@gmail.com 
Pós-Doutorado em Saúde Coletiva pela Universidade Federal da Bahia (UFBA)

Doutorado em Saúde Coletiva pela Universidade do Estado do Rio de Janeiro (UERJ)

Professora do Programa de Pós-Graduação em Saúde Coletiva e do Mestrado Acadêmico em Serviço Social na Universidade Estadual do Ceará (UECE)

\section{UECE}

Avenida Dr. Silas Munguba, 1700, Campus do Itaperi

Fortaleza - Ceará - Brasil

CEP: 60.714-903 